\title{
RESEARCH
}

\section{Impact of Communication Method and Timeliness on Student and Faculty Perception of Professionalism and Value}

\author{
Adam N. Pate, PharmD, ${ }^{\text {a,b }}$ Laurie Fleming, PharmD, ${ }^{a}$ Ashley Jones-Bodie, $\mathrm{PhD},{ }^{\mathrm{c}}$ Jamie L. Wagner, PharmD, ${ }^{\mathrm{a}}$ \\ Joshua W. Fleming, PharmD, ${ }^{a}$ Courtney Davis, PharmD, ${ }^{a}$ Meagan A. Brown, PharmD ${ }^{\text {a }}$ \\ ${ }^{a}$ The University of Mississippi, School of Pharmacy, University, Mississippi \\ ${ }^{\mathrm{b}}$ Editorial Board Member, American Journal of Pharmaceutical Education, Arlington, Virginia \\ ${ }^{c}$ The University of Mississippi, Department of Writing and Rhetoric, University, Mississippi
}

Corresponding Author: Adam N. Pate, The University of Mississippi, School of Pharmacy, P.O. Box 1848, University, MS 38677. Tel: 662-915-8747. Email: anpate@ olemiss.edu

Submitted September 14, 2020; accepted June 16, 2021; ePublished July 2021

Objective. This study sought to evaluate faculty/preceptor and student perceptions regarding preferences and timeliness of communication on professionalism and value.

Methods. An anonymous questionnaire was sent to faculty/preceptors and students evaluating preferred method of communication, response time expectations, impact on professionalism, and perception of being valued. The University of Mississippi Institutional Review Board granted expedited approval.

Results. A total of 253/924 responses were received (27\% response rate). Responses came from 27 (11\%) full-time faculty, 94 (37\%) preceptors, and $132(52 \%)$ students. Overall, email was the preferred communication method for nontime sensitive information (98\%) with a majority of faculty/preceptors and students indicating 48hrs was a reasonable response time. Participants largely felt $<24$ hours to be a reasonable response time for text or phone call communication. Most students indicated response time to be somewhat or not impactful (58\%) on their view of professionalism, while faculty and preceptors indicated response time to be neutral or somewhat impactful (60\%). The majority of students (77\%) felt that the response time from faculty/preceptors impacted their perceptions of feeling valued and important. Conclusion. Communication preferences among faculty/preceptors and students differ. Professionalism related to communication is important for all groups, and timeliness in communication between faculty, preceptors, and students impacts perception of value and self-worth.

Keywords: communication, student services, professionalism, confirmation, self-worth

\section{INTRODUCTION}

Communication plays a critical role in how we are perceived and has significant potential to positively or negatively impact those with whom we interact. Pharmacy faculty/preceptors and students communicate with each other in a variety of ways and often face challenges that may impede effective communication. Methods and practices of communication can impact feelings of value and self-worth as well as general perceptions of one's colleagues. The "always on" culture of today, where one might communicate via multiple channels throughout the day, has altered communication expectations and can lead to communication overload and fatigue, in some cases resulting in delayed communication response times. ${ }^{1,2}$ In addition, assumptions regarding preferred communication method (eg, email, text, phone), work-life balance, after-hours contact, and what constitutes a "timely response" may vary among faculty, preceptors, and students. To date, these communication barriers and challenges have not been thoroughly examined in pharmacy education and may have a larger impact than is realized regarding perception of professionalism and subjective feelings of self-worth or confirmation among students and faculty/preceptors.

Over a number of decades, instructional communication research has demonstrated correlations between effective communication and student success in both broad theoretical terms and in narrowed application-based study of teacher behaviors. ${ }^{3}$ For example, research into the impact of instructor email response speeds (chronemics) has found that faculty who responded faster to student emails were more positively evaluated by students regardless of the actual content in the email response. ${ }^{4}$ Foral et al. have been among the few in pharmacy education to evaluate the impact of expectations in 
email communication on teacher immediacy - the communicative behaviors that decrease the psychological distance between students and teachers ultimately creating a positive learning environment between students and faculty. ${ }^{5}$ Their results indicate that students felt faculty should respond to emails within 24 hours, faculty overestimated their accessibility and approachability compared to student perception, and that email communication can foster teacher immediacy even when faculty and student are not on the same physical campus. ${ }^{5}$ Much of the other communication literature in pharmacy education focuses on teaching students how to better communicate with patients, providers, etc. but there is a dearth of research evaluating the impact of communication between faculty/preceptors and students. ${ }^{6-8}$

The communication concept of immediacy has captured much of the attention in communication education research. ${ }^{9-12}$ These findings have led to an increased understanding of behaviors teachers can enact to positively impact student outcomes. In contrast, teacher confirmation defined as teacher behaviors that confirm students as valuable, significant individuals, though not as broadly explored has evolved as a distinct concept and broad theory in the field of instructional communication research. ${ }^{13}$ Though some conceptual and outcome focused overlap exists between teacher immediacy and teacher confirmation, these concepts have distinctive foci - one focused on closeness (immediacy) and one focused on affirmation of the individual's value and worth (confirmation). Prior researchers have argued that teacher confirmation is a broader theoretical construct that subsumes many teacher behaviors including immediacy. ${ }^{14,15}$ Research within the study of perceived teacher confirmation has shown positive relationships to student learning, motivation, and apprehension in the classroom. ${ }^{13}$ Additionally, research has indicated that perceived teacher confirmation is linked to improved student communication, participation, and greater learning. ${ }^{16}$

When examining research beyond the bounds of instructional communication and pharmacy literature, the authors were unable to find work in other health professions evaluating this relationship between faculty/preceptor and student, although examples evaluating immediacy in the patient provider relationship are available. ${ }^{17}$ In addition to the absence of studies focused on teacher confirmation in pharmacy literature, to date, research in pharmacy education has not evaluated preferred communication method (text, phone, email), expectations of responsiveness based on communication method or time sensitive or non-sensitive nature of the information, or perception of professionalism and confirmation between faculty/preceptors and students. Based on these research findings and the current absence of recent research examining impact of confirmation in communication between faculty/preceptors and students in the pharmacy literature, it may be helpful to explore teacher confirmation as part of the faculty/preceptor and student interaction. This research project sought to answer questions broadly exploring communication preferences and related impacts concerning perception of timeliness of response, professionalism, and confirmation between faculty/preceptors and students.

\section{METHODS}

This was an Institutional Review Board (IRB)-approved, cross-sectional study which utilized an anonymous electronic questionnaire to determine preferences of communication methods, perception of timeliness of communication, perceptions of professionalism, and impact of response time on individual confirmation. Upon review of the current literature, there was no validated survey instrument that addressed the specific aims of this study. The research team developed two identical 25-item questionnaires - one targeting students and the other targeting faculty/preceptors. Globally the questionnaire assessed five areas: 1) participants' preferred method of communication (email, telephone, virtual, text, in-person), 2) if the preferred communication method changed based on time sensitivity of information, 3) variation of expected response time (less than one hour, 1-24 hours, 25-48 hours, 49-72 hours, more than 72 hours) based on method of communication, 4) communication method impact on perceptions of professionalism (eg, is texting unprofessional), and 5) impact of email response time on individual confirmation (eg, does a faster response improve feelings of self-worth and value). In addition to faculty/preceptor communication the questionnaire sought to identify variation in these areas among faculty/preceptors when communicating with colleagues (faculty/preceptor-tofaculty/preceptor). The questionnaire also collected demographic information of participants.

Between November 2019 and December 2019, the anonymous questionnaire was delivered using Qualtrics (Qualtrics Provo, UT) to active full-time faculty, part-time faculty preceptors, and currently enrolled first- through fourthyear students at the University Of Mississippi School Of Pharmacy. Participants received one reminder within a two-week period before data collection was closed. Responses were analyzed for each of the five main areas with faculty/preceptor responses being further analyzed for impacts on peer-to-peer communication. Categorical data was analyzed using ChiSquare or Fischer's Exact test as appropriate, and continuous data was analyzed using Student's T-test or Mann-Whitney U test, as appropriate. SPSS version 26.0 (IBM, Chicago, IL) was used to analyze all data. 


\section{RESULTS}

A total of 253 participants responded to the survey from a pool of 924 (27\% response rate). This response rate is typical at our institution for faculty/preceptors and students based on prior surveys sent to these groups (40\% and $20 \%$, respectively). When broken down by participant type, 121/253 (48\%) of participants were full-time faculty/preceptors and 132/253 (52\%) were student participants. Primary statistical analysis was performed using two distinct groups faculty/preceptors and students. Overall, faculty/preceptor participants were well-represented, including those with fewer than five years to more than forty years of experience. Student representation was distributed relatively equal amongst each class (19.7\% first year, $29.5 \%$ second year, $25 \%$ third year, and $25.8 \%$ fourth year, respectively).

Overall, a majority of all participants preferred email (89\%) over other methods for non-time sensitive communication. Conversely, when communicating time-sensitive information, $35 \%$ of all participants' preferred a faceto-face, in-person meeting, followed by text messaging (28\%), email (21\%), and lastly, phone call (16\%). Variation in most preferred method for time sensitive information existed between faculty/preceptors and students. A more detailed breakdown of these preferences can be found in Table 1.

Evaluating method of communication and expected response time showed variation between faculty/preceptors and students. Reasonable response times were categorized by communication method and by time. When faculty/preceptors and students communicate via email, a majority of all participants (91\%) consider 48 hours to be a reasonable response time, but over half of the student participants $(62 \%)$ indicated 24 hours to be a reasonable response time for an email response from faculty/preceptors. When communicating by text message, almost all participants (95\%) believed within 24 hours to be a reasonable response time. Similarly a majority of participants expect a phone call to be returned within 24 hours (91\%). If faculty/preceptor to student communication occurs after the workday or over the weekend, $88 \%$ of participants expect a slower response compared to communication during standard work times.

Researchers also evaluated professionalism in faculty/preceptor and student communication. The majority of all participants deemed professionalism in communication to be important or very important (94\%) (Table 2). Most participants (69\%) also agreed that a communication response outside of their ideal time frame impacted their perception of the respondent's professionalism. In contrast, a minority of overall participants $(13 \%)$ indicated that communication received outside their preferred method (text vs email, etc.) would impact their view of a respondents' professionalism. When self-reflecting on instances where they individually responded outside of their preferred time frame (eg, responding later than they would consider ideal), $75 \%$ of participants indicated that they view their own behavior in this context as unprofessional.

In addition to exploring preferences regarding type of communication method, timeliness of response, and views of professionalism, this project also explored participants' perceptions of confirmation (ie, feelings of value and significance as an individual) as a component of email response timeliness. Nearly $80 \%$ of students indicated that faculty/preceptor email response time impacts their feeling of value/importance as an individual. Slightly over $80 \%$ of students indicated that the email response time of faculty/preceptors impacts their view of if the faculty member/preceptor values them as a student/their learning. Similarly when examining students' perception of confirmation with peer communication, $80 \%$ indicated that the amount of time it takes for fellow students to respond would impact their perception of being valued. Further breakdown of response time on confirmation can be found in Table 3 .

An additional sub analysis for communication method preferences and response times was performed separating students into P1-P3 vs. P4 as well as full time faculty vs preceptors. Student sub analysis found that the only statistically significant variation in responses as compared to the above was that more P4 students prefer email (32.4\%) for non-time sensitive information than P1-P3 students and P1-P3 students were more likely (41.2\% vs. 20.6\%) to consider $<1$ hour was a reasonable response time to a phone call.

When communicating peer-to-peer (faculty/preceptor-to-faculty/preceptor) about non-time sensitive information, faculty/preceptors largely preferred email (88\%). These preferences changed for time sensitive information where faculty/preceptors prefer phone call (41\%), text (36\%), or face to face meeting (16\%). Analysis by peer group with timesensitive vs. non-sensitive information between peers can be found in Table 4.

Overall, faculty members and preceptors placed a high degree of importance on professionalism when referring to colleagues. (90\% important/very important) (Table 4). Most faculty/preceptors indicated that their perception of their peers' professionalism ranged from neutral to not impactful if communication was received outside of their preferred method $(93 \%)$ or outside their preferred time frame (81\%). A majority of faculty/preceptor participants $(81 \%)$ indicated they occasionally, rarely, or never felt it was an act of unprofessionalism if they responded to peer communication outside 
their preferred time frame, and only $4 \%$ felt that receiving peer communication after hours or over the weekend was unprofessional behavior.

Analyzing faculty/preceptor peer communication for impact on confirmation indicated that the amount of time it took a colleague to respond to an email would impact their perception of how much their peer values the correspondence (59\% faculty vs $67 \%$ preceptor). Additionally, one third of faculty/preceptors indicated that peer response time impacted their personal feeling of value as an individual (Table 3).

\section{DISCUSSION}

Technical communication considerations like method of communication, timeliness of response, and time sensitive nature of communication are important aspects of our ability to be effective and respectful colleagues and educators. This research explored the impact of preferred method of communication on views of professionalism and perceptions of confirmation among faculty/preceptors, and students. It also evaluated these perceptions in relation to response time, after hours communication, and peer to-peer communication. These findings fill a gap in the pharmacy education and communication literature through more broadly evaluating variations and impacts of these variables on all participants (student and faculty/preceptors). This research also is the first to examine the impact of email response time on confirmation for both faculty/preceptors and students in peer and non-peer relationships.

This study corroborates previous research findings regarding communication preferences among students and provides detailed information useful for students and faculty. Overall, students' default communication method preference from faculty/preceptors on non-time-sensitive information is via email. Students' preferred method of communication only changed for communicating time-sensitive information with faculty/preceptors; in this context, more students preferred face-to-face, in-person meetings. This result was encouraging in that it validates that face-to-face communication is still valued by students, and in some instances, is preferred. This preference could be the result of many factors which were not evaluated in this study such as students' interest in the ability to ask follow-up questions and gain clarity on time sensitive matters, students' desire for personal connection with faculty/preceptors, students' valuing of face-to-face communication with faculty/preceptors, possibly a sense of being overwhelmed by email communication, or perhaps fear of missing important information and/or nonverbal indicators in other communication methods.

When evaluating timeliness of responses, perceptions of a timely response between faculty/preceptors and students varied minimally across the various communication methods. More participants generally indicated that $<1$ hour would be a reasonable response time when communicating by text or phone call as compared to email, but still the majority felt $<24$ hours was appropriate. One interesting finding found in Table 2 is that over $80 \%$ of faculty/preceptors occasionally, rarely, or never felt they were acting unprofessional if they responded to students outside of their ideal response time. On the contrary slightly over $50 \%$ of students frequently or very frequently felt this would be unprofessional. This finding seems to be in opposition to the fact that professionalism in communication was ranked high amongst all groups. Regarding communication occurring after the standard workday or on the weekend, respondents overwhelmingly did not view this communication practice as unprofessional, with a majority expecting a longer response than for communication occurring during general business hours.

Impacts of email timeliness on faculty member/preceptor, and student perception of confirmation found that participants associated feelings of self-worth and perceptions of the receiver inherently valuing their communication are impacted by delayed response times. Faculty member and preceptor confirmation was also impacted by timeliness of peer response with approximately one-third of faculty or preceptors attributing their personal value as a colleague based on timeliness of an email response. The degree of confirmation impact by timeliness of response was surprising to investigators and may be the result of a variety of unintended consequences inherent to faculty and preceptor work (ie, disconnecting from electronic communication during meetings, busy times at work, or patient care-related activities). Clear expectations regarding communication have the potential to improve not only communication but also student and colleague perceptions of being valued.

The results of this study may provide guidance for best practices in communication regarding method of communication, timeliness of response, and considerations for time sensitive vs non-sensitive information. Additionally, they may shed light on a blind spot for some faculty regarding the importance and impact of timely communication with students and peers. In general, it would appear prudent to respond to all communication within 24 hours during weekdays and consider replying sooner for text communication if possible. Students also may not need worry as much regarding which communication medium they should use with faculty members/preceptors as text, email, or phone call did not significantly impact views of professionalism and were varied based on time sensitive nature of communication. Although 
these general parameters may be difficult for faculty, preceptors, and students at certain times of the year and may not apply to sensitive email communication, the general understanding that response times communicate a great deal to our peers and students concerning how much we value them as individuals and value their communication is important to keep in mind.

This study is unique in that it evaluated two groups: full-time faculty members/preceptors, and students. Additionally, it is the first in pharmacy education to evaluate preferences for modes of communication based on time sensitive material, along with evaluating perception of professionalism and impact on confirmation. As with any study, there are limitations that need to be addressed. This was a single institution project completed at a traditional 4-year split campus institution located in the Southeastern United States potentially limiting generalizability. Additionally, the potential for responder bias should be considered when interpreting these results. The survey also had a $27 \%$ response rate limiting ability to draw firm conclusions regarding communication broadly even though the sample was evenly divided between faculty/preceptors and students. Lastly, in evaluating time frames for response of less than one hour to less than 24 hours represents a wide range where faculty/preceptors or students might need a timelier response. In future studies, it may be beneficial to evaluate less than an hour, 4-8 hours, or less than 24 hours to get a better understanding of response times during a usual working day.

Researchers hope that this pilot project stimulates further research into interpersonal communication within the academy. Opportunities the researchers believe would be interesting include a multi-institution replication study including 3-year, 4-year, split campus, and other schools to confirm findings, impact of out-of-office replies on confirmation, and in general further research into the area of confirmation in areas like the pharmacy classroom, clinical sites, etc. Another area that could be considered in future communication research is the location of student classrooms or meeting areas in relation to faculty offices to see if student communication preferences (eg, face-to-face meetings) differ based on convenience of faculty offices. In the institution this research was conducted, students frequently pass faculty offices as they go to their classrooms lending itself to ease of in-person communication. While this specific aspect was not examined in this study, it may provide explanation for this result and should be considered for future research. An area of consideration for faculty/preceptors would be their consideration of response time to students as approximately $40 \%$ did not feel as if they were acting unprofessionally when responding outside of their own ideal time frame. Perhaps enhanced communication with students when workload is heavier and response times may be delayed is warranted given that the majority of students felt more strongly about acting unprofessionally when responding outside of the ideal time frame. Additionally, researchers did not define direction of the impact on perceptions, etc. in this study and this may be evaluated further in future studies. Another finding from this research that warrants further investigation is weekend and afterhours communication having minimal impact on views of professionalism, especially when considering this finding alongside the burden of burnout on pharmacy educators and broad implications of excessive workload. ${ }^{18}$

\section{CONCLUSION}

Findings from this study expand our understanding of the importance and impact of timely responses when faculty, preceptors, and students are communicating with each other in that all participants, and specifically an overwhelming majority of students, attributed timeliness of communication response to perceptions of value/importance as an individual. In fact, timeliness of response appears to be more important than the actual method of communication for all participants. Understanding this potential broader impact of timeliness of responses allows individuals an opportunity to manage expectations and provides an additional avenue for cultivating an individual sense of value and importance in students, faculty, and preceptors thus contributing to the overall benefits of teacher confirmation indicated by prior research. Especially in times of uncertainty and when the teaching landscape changes for both faculty and students, as has been clearly seen during the COVID-19 pandemic with shifting of instruction to the online setting, these findings may become even more important. When modes of communication are removed from the faculty toolkit (eg, in-person interactions during times of a crisis), it may be even more critical for faculty to rely on the positive, communicative behaviors that are available to faculty which support confirmation. ${ }^{16,17}$ These findings demonstrate that timely responses to peer and non-peer emails are one such avenue.

\section{REFERENCES}

1. Hemp P. Death by Information Overload. Harv Bus Rev. 2009;(September 2009). Accessed June13, 2021. https://hbr.org/2009/09/death-by-information-overload 
2. Russell E, Woods SA. Personality differences as predictors of action-goal relationships in work-email activity. Comput Hum Behav. 2020;103:67-79. doi:10.1016/j.chb.2019.09.022

3. Witt PL, Wheeless LR, Allen M. A meta-analytical review of the relationship between teacher immediacy and student learning. Commun Monogr. 2004;71(2):184-207. doi:10.1080/036452042000228054

4. Andersen JF. Teacher Immediacy as a Predictor of Teaching Effectiveness. Ann Int Commun Assoc. 1979;3(1):543559. doi:10.1080/23808985.1979.11923782

5. Foral PA, Turner PD, Monaghan MS, et al. Faculty and Student Expectations and Perceptions of E-mail Communication in a Campus and Distance Doctor of Pharmacy Program. Am J Pharm Educ. 2010;74(10). doi:10.5688/aj7410191

6. Kostoff M, Burkhardt C, Winter A, Shrader S. An Interprofessional Simulation Using the SBAR Communication Tool. Am J Pharm Educ. 2016;80(9):157. doi:10.5688/ajpe809157

7. Gillette C, Rudolph M, Rockich-Winston N, Stanton R, Anderson HG. Improving Pharmacy Student Communication Outcomes Using Standardized Patients. Am J Pharm Educ. 2017;81(6):110. doi:10.5688/ajpe816110

8. Hess R, Hagemeier NE, Blackwelder R, Rose D, Ansari N, Branham T. Teaching Communication Skills to Medical and Pharmacy Students Through a Blended Learning Course. Am J Pharm Educ. 2016;80(4):64. doi:10.5688/ajpe80464

9. Roberts A, Friedman D. The Impact of Teacher Immediacy on Student Participation: An Objective CrossDisciplinary Examination. Int J Teach Learn High Educ. 2013;25(1):38-46.

10. Sanders JA, Wiseman RL. The effects of verbal and nonverbal teacher immediacy on perceived cognitive, affective, and behavioral learning in the multicultural classroom. Commun Educ. 1990;39(4):341-353. doi:10.1080/03634529009378814

11. King P, Witt P. Teacher Immediacy, Confidence Testing, and the Measurement of Cognitive Learning. Commun Educ. 2009;58(1):110-123. doi:10.1080/03634520802511233

12. Kelly S, Rice C, Wyatt B, Ducking J, Denton Z. Teacher Immediacy and Decreased Student Quantitative Reasoning Anxiety: The Mediating Effect of Perception. Commun Educ. 2015;64(2):171-186. doi:10.1080/03634523.2015.1014383

13. Ellis K. Perceived Teacher ConfirmationThe Development and Validation of an Instrument and Two Studies of the Relationship to Cognitive and Affective Learning. Hum Commun Res. 2000;26(2):264-291. doi:10.1111/j.14682958.2000.tb00758.x

14. Ellis K. The impact of perceived teacher confirmation on receiver apprehension, motivation, and learning. Commun Educ. 2004;53(1):null. doi:10.1080/0363452032000135742

15. Jones-Bodie A, Morgan M. Confirmation, immediacy, and motivation in the classroom: A longitudinal exploration of teacher confirmation, immediacy and student motivation. Paper presented at the. Presented at the: annual conference of the Southern States Communication Association; March 2007; Louisville, KY.

16. Goodboy AK, Myers SA. The Effect of Teacher Confirmation on Student Communication and Learning Outcomes. Commun Educ. 2008;57(2):153-179. doi:10.1080/03634520701787777

17. Bartlett Ellis R, Carmon A, Pike C. A review of immediacy and implications for provider-patient relationships to support medication management. Patient Prefer Adherence. Published online January 2016. doi:10.2147/PPA.S95163

18. Darbishire P, Isaacs AN, Miller ML. Faculty Burnout in Pharmacy Education. Am J Pharm Educ. 2020;84(7):ajpe7925. doi:10.5688/ajpe7925 
Table 1.Communication preferences between Faculty/Preceptor and Student

\begin{tabular}{|c|c|c|c|}
\hline & $\begin{array}{c}\text { Total } \\
(\mathrm{n}=\mathbf{2 5 3}, \mathbf{n} \%)\end{array}$ & $\begin{array}{l}\text { Faculty/Preceptors } \\
\quad(\mathbf{n}=121, \mathbf{n} \%)\end{array}$ & $\begin{array}{c}\text { Students } \\
(\mathbf{n}=\mathbf{1 3 2}, \mathbf{n} \%)\end{array}$ \\
\hline \multicolumn{4}{|c|}{$\begin{array}{l}\text { What communication method do you prefer most when communicating for information that is NOT time sensitive } \\
(\mathrm{n}=252)\end{array}$} \\
\hline Phone call & $2(0.8)$ & $2(1.7)$ & $0(0)$ \\
\hline Email & $223(88.5)$ & $111(92.5)$ & $112(84.8)$ \\
\hline $\operatorname{Text}^{\mathrm{a}}$ & $5(2)$ & $5(4.2)$ & $0(0)$ \\
\hline Face-to-face in-person ${ }^{a}$ & $22(8.7)$ & $2(1.7)$ & $20(15.2)$ \\
\hline \multicolumn{4}{|c|}{$\begin{array}{l}\text { What communication method do you most prefer most when communicating for information that is time sensitive } \\
(\mathrm{n}=252)\end{array}$} \\
\hline Phone call ${ }^{\mathrm{a}}$ & $40(15.9)$ & $29(24.2)$ & $11(8.3)$ \\
\hline Email & $52(20.6)$ & $27(22.5)$ & $25(18.9)$ \\
\hline Text $^{*}$ & $71(28.2)$ & $45(37.5)$ & $26(19.7)$ \\
\hline Face-to-face in-person ${ }^{a}$ & $89(35.3)$ & $19(15.8)$ & $70(53)$ \\
\hline \multicolumn{4}{|c|}{ When referring to communication by Email, what are reasonable response times (ideal time frame)? $(\mathrm{n}=252)$} \\
\hline$<1$ hour & $4(1.6)$ & $0(0)$ & $4(3)$ \\
\hline $1-24$ hours $^{\text {a }}$ & $133(52.8)$ & $51(42.5)$ & $82(62.1)$ \\
\hline $25-48$ hours $^{\text {a }}$ & $98(38.9)$ & $58(48.3)$ & $40(30.3)$ \\
\hline 49-72 hours & $16(6.3)$ & $10(8.3)$ & $6(4.5)$ \\
\hline$>72$ hours & $1(0.4)$ & $1(0.8)$ & $0(0)$ \\
\hline \multicolumn{4}{|c|}{ When referring to communication by Text, what are reasonable response times (ideal time frame)? $(\mathrm{n}=248)$} \\
\hline$<1$ hour $^{\mathrm{a}}$ & $84(33.9)$ & $31(26.7)$ & $53(40.2)$ \\
\hline 1-24 hours & $156(62.9)$ & $80(69)$ & $76(57.6)$ \\
\hline 25-48 hours & $6(2.4)$ & $3(2.6)$ & $3(2.3)$ \\
\hline 49-72 hours & $1(0.4)$ & $1(0.9)$ & $0(0)$ \\
\hline$>72$ hours & $1(0.4)$ & $1(0.9) \quad 2$ & $0(0)$ \\
\hline \multicolumn{4}{|c|}{ When referring to communication by Phone Call, what are reasonable response times (ideal time frame)? $(\mathrm{n}=251)$} \\
\hline$<1$ hour & $66(26.3)$ & $29(24.4)$ & $37(28)$ \\
\hline 1-24 hours & $164(65.3)$ & $78(65.5)$ & $86(65.2)$ \\
\hline 25-48 hours & $16(6.4)$ & $8(6.7)$ & $8(6.1)$ \\
\hline 49-72 hours & $4(1.6)$ & $3(2.5)$ & $1(0.8)$ \\
\hline$>72$ hours & $1(0.4)$ & $1(0.8)$ & $0(0)$ \\
\hline \multicolumn{4}{|c|}{$\begin{array}{l}\text { How does your ideal time frame for a response change if the communication occurs after the workday or during th } \\
\text { weekend? }(n=252)\end{array}$} \\
\hline Expect quicker response time & $7(2.8)$ & $3(2.5)$ & $4(3)$ \\
\hline Expect the same response time* & $22(8.7)$ & $16(13.3)$ & $6(4.5)$ \\
\hline Expect a longer response time* & $223(88.5)$ & $101(84.2)$ & $122(92.4)$ \\
\hline
\end{tabular}

${ }^{\mathrm{a}}$ Denotes $p<.05$. 
Table 2. Professionalism Views for Communication between Faculty/Preceptors and Students

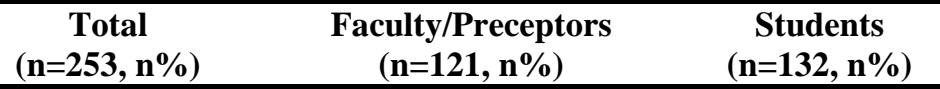

How does your ideal time frame for response from non-peers change if the communication occurs after the workday or during the weekend? $(n=252)$
Expect quicker response time
7 (2.8)
$22(8.7)$
Expect the same response time ${ }^{a}$
$223(88.5)$
3 (2.5)
$4(3)$
$16(13.3)$
$101(84.2)$
$6(4.5)$
Expect a longer response time ${ }^{\text {a }}$
to non-peers?
Not at all important
$1(0.4)$
$0(0)$
$122(92.4)$
Somewhat important
9 (3.6)
$5(4.1)$
$1(0.8)$
Neutral $^{\text {a }}$
$6(2.4)$
$0(0)$
4 (3)
$64(25.3)$
Important
$173(68.4)$
$30(24.8)$
$6(4.5)$
$86(71.1)$
$34(25.8)$
$87(65.9)$

If you receive communication from non-peers outside of your preferred method, how greatly does this impact your perception of their professionalism as it relates to communication?
Not impactful ${ }^{\text {a }}$
$76(30)$
28 (23.1)
48 (36.4)
Somewhat impactful ${ }^{\mathrm{a}}$
$56(22.1)$
37 (30.6)
$19(14.4)$
Neutral
87 (34.4)
37 (30.6)
$50(37.9)$
$29(11.5)$
$18(14.9)$
$11(8.3)$
Very impactful
5 (2)
$1(0.8)$
$4(3)$

If you receive a response from non-peers outside of your ideal time frame, how greatly does this impact your perception of their professionalism as it relates to communication? $(n=252)$
Not impactful
37 (14.7)
$18(15)$
$19(14.4)$
Somewhat impactful
85 (33.7)
Neutral
40 (15.9)
Impactful
$71(28.2)$
43 (35.8)
42 (31.8)
$21(17.5)$
19 (14.4)
19 (7.5)
33 (27.5)
38 (28.8)
5 (4.2)
14 (10.6)

If your own response to non-peers is outside of your ideal time frame, does this make you feel as if you are acting in an unprofessional manner? $(\mathrm{n}=252)$
Never $^{\mathrm{a}}$
Rarely $^{\text {a }}$
$13(5.2)$
48 (19)
Occasionally
$100(39.7)$
Frequently $^{\mathrm{a}}$
64 (25.4)
$27(10.7)$
$10(8.3)$
$35(29.2)$
$55(45.8)$
$17(14.2)$
$3(2.5)$
Very frequently

$3(2.3)$

$13(9.8)$

45 (34.1)

47 (35.6)

${ }^{\mathrm{a}}$ Denotes $p<.05$. 
Table 3. Impact of Communication on Confirmation (Self-Worth/Value)

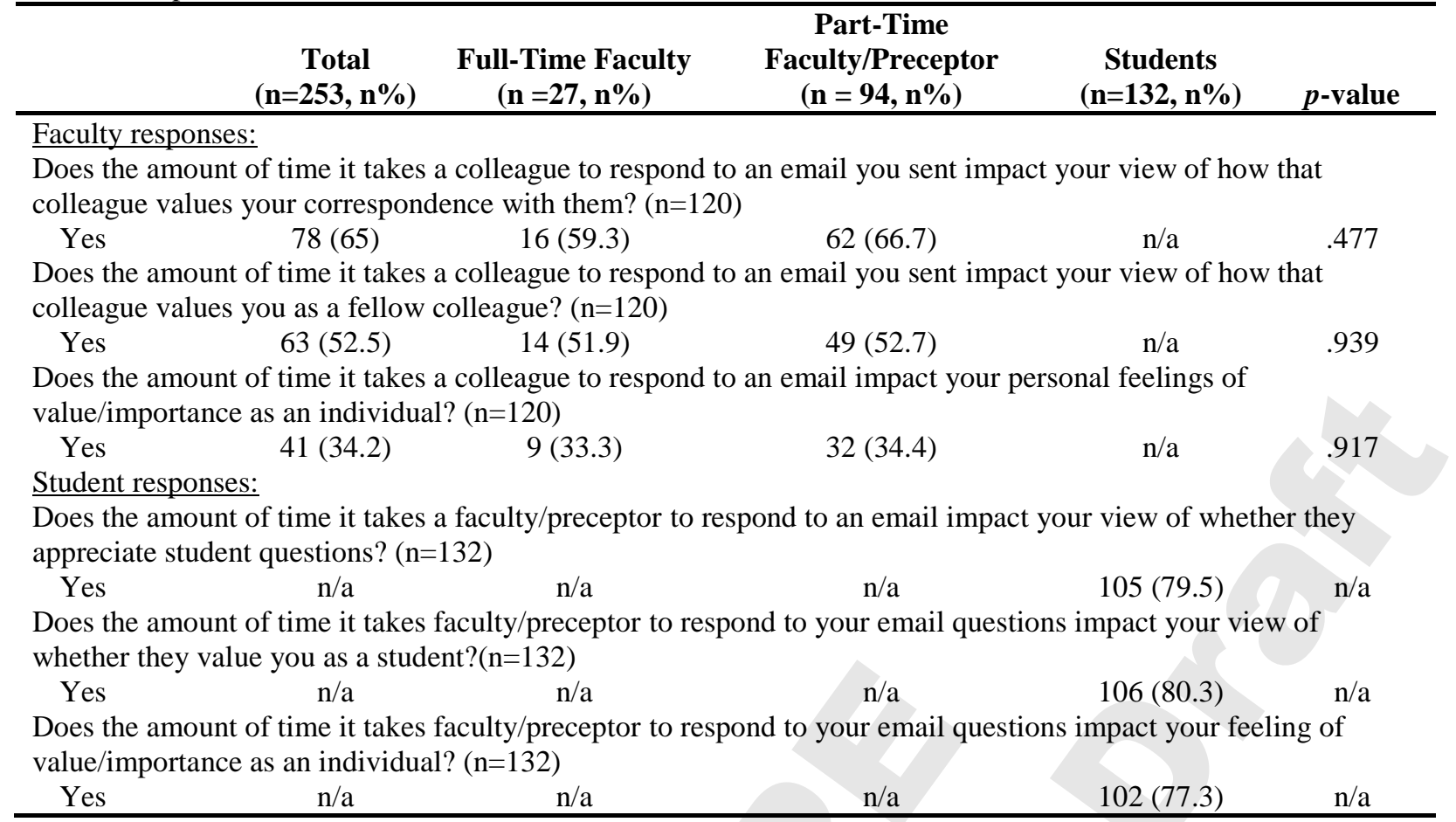


Table 4. Communication Preferences in Faculty and Preceptor peer communication.

\begin{tabular}{|c|c|c|c|}
\hline & $\begin{array}{c}\text { Total } \\
(\mathrm{n}=121, \mathbf{n} \%)\end{array}$ & $\begin{array}{c}\text { Faculty } \\
(\mathrm{n}=27, \mathrm{n} \%)\end{array}$ & $\begin{array}{l}\text { Preceptors } \\
(\mathrm{n}=94, \mathrm{n} \%)\end{array}$ \\
\hline \multicolumn{4}{|c|}{ What communication method do you prefer most when communicating information that is NOT time sensitive? } \\
\hline Phone call & $2(1.7)$ & $0(0)$ & $2(2.1$ \\
\hline Email & $107(88.4)$ & $24(88.9)$ & $83(88.3)$ \\
\hline Text & $5(4.1)$ & $0(0)$ & $5(5.3)$ \\
\hline Face-to-face in-person & $7(5.8)$ & $3(11.1)$ & $4(4.3)$ \\
\hline \multicolumn{4}{|c|}{ What communication method do you most prefer most when communicating information that is time sensitive? } \\
\hline Phone call* & $49(40.5)$ & $6(22.2)$ & $43(45.7)$ \\
\hline Email & $8(6.6)$ & $4(14.8)$ & $4(4.3)$ \\
\hline Text & $44(36.4)$ & $7(25.9)$ & $37(39.4)$ \\
\hline Face-to-face in-person* & $20(16.5)$ & $10(37)$ & $10(10.6)$ \\
\hline \multicolumn{4}{|c|}{ When referring to communication by Email, what are reasonable response times (ideal time frame)? } \\
\hline $1-24$ hours & $53(43.8)$ & $14(51.9)$ & $39(41.5)$ \\
\hline 25-48 hours & $55(45.5)$ & $11(40.7)$ & $44(46.8)$ \\
\hline 49-72 hours & $10(8.3)$ & $1(3.7)$ & $9(9.6)$ \\
\hline$>72$ hours & $3(2.5)$ & $1(3.7)$ & $2(2.1)$ \\
\hline \multicolumn{4}{|c|}{ When referring to communication by Text, what are reasonable response times (ideal time frame)? $(\mathrm{n}=120)$} \\
\hline$<1$ hour & $36(30)$ & $10(38.5)$ & $26(27.7)$ \\
\hline 1-24 hours & $81(67.5)$ & $15(57.7)$ & $66(70.2)$ \\
\hline 25-48 hours & $2(1.7)$ & $1(3.8)$ & $1(1.1)$ \\
\hline$>72$ hours & $1(0.8)$ & $0(0)$ & $1(1.1)$ \\
\hline \multicolumn{4}{|c|}{ When referring to communication by Phone Call, what are reasonable response times (ideal time frame)? } \\
\hline$<1$ hour & $33(27.3)$ & $5(18.5)$ & $28(29.8)$ \\
\hline 1-24 hours & $77(63.6)$ & $16(59.3)$ & $61(64.9)$ \\
\hline 25-48 hours* & $8(6.6)$ & $6(22.2)$ & $2(2.1)$ \\
\hline 49-72 hours & $2(1.7)$ & $0(0)$ & $2(2.1)$ \\
\hline$>72$ hours & $1(0.8)$ & $0(0)$ & $1(1.1)$ \\
\hline \multicolumn{4}{|c|}{$\begin{array}{l}\text { How does your ideal time frame for response change if the communication occurs after the workday or during the } \\
\text { weekend? }\end{array}$} \\
\hline Expect quicker response time & $4(3.3)$ & $1(3.7)$ & $3(3.2)$ \\
\hline Expect the same response time & $8(6.6)$ & $0(0)$ & $8(8.5)$ \\
\hline Expect a longer response time & $109(90.1)$ & $26(96.3)$ & $83(88.3)$ \\
\hline
\end{tabular}

*Denotes $p<.05$. 